Trabajos y Comunicaciones, 2da. Época, No 48, e062, julio-diciembre 2018. ISSN 2346-8971

Universidad Nacional de La Plata.

Facultad de Humanidades y Ciencias de la Educación.

Departamento de Historia

\title{
Los primeros delegados del Departamento del Trabajo bonaerense en el interior provincial (1917-1922)*
}

\section{Luciano Barandiarán *}

* Universidad Nacional del Centro de la Provincia de Buenos Aires CONICET, Argentina lubarfe@gmail.com

Cita sugerida: Barandiarán, L. (2018). Los primeros delegados del Departamento del Trabajo bonaerense en el interior provincial (1917-1922). Trabajos y Comunicaciones (48), e062. https://doi.org/10.24215/23468971e062

Recibido: 15 de octubre de 2016 I Aceptado: 30 de mayo de 2018 I Publicado: 27 de julio de 2018

(c) (1) (2) Esta obra está bajo licencia Creative Commons Atribución-NoComercial-CompartirIgual 4.0 Internacional http://creativecommons.org/licenses/by-nc-sa/4.0/deed.es AR 


\section{Los primeros delegados del Departamento del Trabajo bonaerense en el interior} provincial (1917-1922)*

The first delegates of the Department of Labor within the province of Buenos Aires (1917-1922)

Luciano Barandiarán

Universidad Nacional del Centro de la Provincia de Buenos Aires -

CONICET, Argentina

lubarfe@gmail.com

\section{Resumen:}

Este trabajo analiza la influencia del Departamento del Trabajo de la Provincia de Buenos Airesenel interior provincial a inicios de la década de 1920. Aquí se estudia la experiencia poco conocidade los delegadoslocales, a diferencia de lo que ha acontecido con la figura de los inspectores. La historiografía ha analizado la influencia del DPT desde el marco provincial, por lo cual aquí abordaremos su incidencia a partir de reducir la escala de observación al plano local. Para ello tomaremos como estudio de caso la ciudad de Tandil, donde hemos podido observar la presencia de tales funcionarios.

Palabras Clave: Intervención estatal; Departamento del Trabajo de la Provincia de Buenos Aires; Trabajadores; Interior provincial.

\section{Abstract:}

This paper analyzes the influence of the Bureau of Labour of the Province of Buenos Airesin the provincial interior at the beginning of the 1920s.Here we studied the experience little known to the local delegates, unlike what has happened with the figure of the inspectors. The historiography has analyzed the influence of the DPT from the provincial context, so try to study their impact from the reduction of the scale of observation to the local level. We will take as a case study the city of Tandil, where we have seen the presence of such officials.

KEYWORDS: State Intervention; Bureau of Labour of the Province of Buenos Aires; Workers; Provincial interior.

\section{INTRODUCCIÓN}

Desde la creación en diciembre de 1916 del Departamento del Trabajo de la Provincia de Buenos Aires (de aquí en más DPT) el gobierno bonaerense pretendió mediaren las relaciones asalariadas bajo su jurisdicción (incluido el interior provincial) no sólo a través de la Policía, agencia estatal que intervenía en la mayor parte de los conflictos laborales hasta ese momento. ${ }^{1}$ Así, se crearon nuevas formas de abordar los temas suscitados por la conflictividad emergente de las relaciones entre capital y trabajo.

En el marco de un proyecto mayor que aborda la influencia en el mencionado espacio del DPT (en especial la circulación y el uso de la información, prácticas y normativas allí elaboradas, así como su impacto sobre las sociedades locales), aquí se aborda algunas formas iniciales a través de las cuales el gobierno intentó intervenir en el mundo del trabajo del interior bonaerense. Además de las iniciativas originadas y desarrolladas desde aquel organismo, la participación, mediación e intervención del Estado provincial sobre el mundo del trabajo se relacionó con procesos vinculados a la trama social en las que intervinieron otros actores sociales, como patrones, obreros y autoridades diversas.

La reducción de escala permite observar mejor la relación de dicho organismo con las sociedades del interior; así también resaltan los vacíos legales propios del mundo del trabajo en las primeras décadas del siglo XX. El modelo de organización política federal del Estado argentino, según el cual era responsabilidad de los gobiernos provinciales la reglamentación y el control de tal legislación (Campione, 2007: 110); y la 
falta de una definición clara acerca de la naturaleza del vínculo laboral (Garzón Rogé, 2013: 131), explican porque hasta mediados de la década de 1940 fueron las provincias y sus respectivas agencias responsables de los asuntos laborales (departamentos y/o bolsas de trabajo, o incluso otras agencias como la Dirección General de Rentas como parece haber sido el caso de Catamarca -Ullivarri, 2013: 159-), los que se hicieron cargo (o no) de los problemas laborales.

El uso de la perspectiva local para abordar la acción estatal en la regulación de las relaciones laborales es necesario para complementar los trabajos existentes sobre las mencionadas reparticiones oficiales, generalmente construidos a partir de lo que aconteció en Capital Federal cuando se ha estudiado la evolución del Departamento Nacional del Trabajo (DNT); o en las capitales provinciales cuando se abordan los diversos departamentos de trabajo creados en las provincias. El uso de la historia local remite a una forma de hacer historia basada en la ya señalada reducción de la escala de observación. La escala micro permite aumentar o disminuir el tamaño del objeto; y modificar la forma y la trama, transformando el contenido de la representación tras elegir lo representable (Revel, 1995: 129). Así, la reducción al nivel local permite el acercamiento a esos espacios a partir de nuevos interrogantes, perspectivas y fuentes, rescatando la riqueza de la diversidad desde la totalidad (Bandieri, 1996: 71). Coincidimos con Revel (1995: 135) en que no existe un corte ni oposición entre historia local e historia global: lo que la experiencia de un individuo, un grupo o un espacio permiten aprehender es una modulación particular de la historia global, una versión original y diferente, más que "una versión atenuada, parcial o mutilada de realidades macro-sociales".

Coincidiendo con esos postulados, aquí se analiza el nombramiento a inicios de la década de 1920 de delegados locales directos del DPT en algunas localidades bonaerenses. El caso bajo estudio se centra en la ciudad de Tandil, cuya heterogénea estructura socio-económica dio a luz en las primeras décadas del siglo XX a un movimiento obrero activo, ante el cual las autoridades provinciales actuaron en función de lo que allí acontecía. En ese marco, abordaremos las acciones desarrolladas por José Fiscalini, un delegado de aquel organismo nombrado para que interviniera en Tandil a inicios de la década de 1920. A partir de dicha actuación procuramos entender como los representantes del DPT se hicieron cargo de espacios y temáticas que hasta ese momento habían sido considerados menos relevantes por parte del Estado provincial. La misma existencia reciente del organismo y el traslado de funcionarios del mismo por el interior provincial indica un cambio en la manera de entender el rol del Estado ante los conflictos laborales por parte de los gobernantes bonaerenses, en este caso radicales. Así, el nuevo organismo asumió la función de vigilar el cumplimiento de las leyes laborales que antes fiscalizaban otras agencias estatales.

Las fuentes utilizadas para desarrollar este artículo son oficiales (decretos, leyes, memorias ministeriales, etc.); y los medios de prensa locales conservados del período, en especial el diario de tendencia radical Nueva Era (NE), que se halla completo para el período bajo estudio; y en menor medida el periódico El Eco de Tandil (ET), de carácter independiente aunque más vinculado a intereses conservadores que solo se editaba jueves y domingo (Barrientos, 1975: 71).

La estructura del texto hace referencia en primer lugar al origen y la evolución del DPT. Posteriormente, se analizan las características de la ciudad y del movimiento obrero tandilense hacia 1920. Finalmente se estudia el accionar de Fiscalini en la ciudad serrana.

\section{INTERVENCIÓN ESTATAL Y MUNDO DEL TRABAJO}

Las instituciones estatales ligadas a las relaciones laborales se conformaron como parte de una compleja trama en las que se combinaron mediaciones políticas y burocráticas, y tensiones internas entre las demandas de la política, la racionalidad técnica, la conflictividad social y la construcción de un marco de regulaciones en el plano laboral (Suriano, 2012: 35). Dicha trama en el escenario público se manifestó a inicios del siglo XX al emerger la llamada "cuestión social", definida como las consecuencias sociales del proceso de inmigración masiva, urbanización e industrialización. A raíz de las manifestaciones del movimiento 
obrero urbano, el Estado aplicó medidas represivas y cooptativas para intervenir en las cuestiones laborales. Así, el gobierno nacional abandonó su tradicional abstención en el campo de las políticas socio-laborales, innovación impulsada, entre otras tendencias, por la corriente de la elite caracterizada como "liberal reformista” por Zimmermann (1995: 15). Junto a medidas represivas, cuyo blanco era el anarquismo, se formularon propuestas para solucionar los problemas del mundo obrero, destacándose el proyecto de Código de Trabajo presentado por Joaquín V. González en 1904 (Suriano, 1989).

Ese proyecto no se sancionó pero fue un indicador del interés creciente del Estado por los problemas socio-laborales. También fue un importante antecedente de la legislación laboral sancionada a posteriori: la creación en 1907 del DNT, dependiente del Ministerio del Interior, se originó en el mencionado proyecto. Su ley orgánica se promulgaría en 1912, esclareciendo y limitando las facultades de sus funcionarios (Auza, 1987). Ante los límites jurisdiccionales del DNT, sus funcionarios intentaron extender su influencia al resto del país estimulando la creación de los departamentos provinciales de trabajo (Suriano, 2012: 41). Posteriormente, ese organismo fue el germen de otros entes nacionales vinculados a similares problemáticas, asociados con los orígenes del peronismo, como la Secretaría de Trabajo y Previsión (STyP), y el Ministerio de Trabajo. $^{2}$

Coincidimos con Ortiz Bergia (2009: 152-153) en que pueden identificarse tres momentos en las políticas laborales articuladas desde el Estado nacional en las primeras décadas del siglo XX:

a) A comienzos de dicho siglo se establecieron medidas de regulación para controlar los conflictos sociales a través de las primeras leyes del trabajo y del DNT, que coexistieron junto a mecanismos represivos hacia los trabajadores.

b) Durante los gobiernos nacionales radicales permaneció el binomio “integración-represión” para tratar la cuestión obrera, incorporándose a través de la política laboral nuevos actores a la sociedad política. Tal objetivo político implicó la intervención del Poder Ejecutivo Nacional en forma selectiva en los conflictos obreros, privilegiando una mediación corporativa.

c) A mediados de la década de 1930 se consolidaron las formas de mediación corporativa en las relaciones sociales y el intervencionismo estatal, perdiendo vigencia la represión como forma predominante de intervenir en los conflictos obreros. ${ }^{3}$

$\mathrm{Al}$ referirse al movimiento obrero en la década de 1930, Korzeniewicz (1993: 323) mencionó que fue una etapa de transición en la que coexistieron viejas y nuevas instituciones y prácticas. Por su parte, Gaudio \& Pilone (1984) sostuvieron que la función mediadora del Estado comenzó en esa década, al considerarse hasta ese momento a las relaciones obrero-patronales como privadas y vinculadas a la esfera de la sociedad civil. Estas reflexiones generan el interrogante de saber cuál fue la función de los organismos públicos dedicados a los problemas obreros en la década de 1920; y si se relacionaron con la sociedad civil, a través de que formas lo hicieron. Lvovich\& Suriano (2006: 18) opinaron al respecto que debe revisarse la idea de que en 1930 se produjo un corte en la formulación de las políticas sociales, postulado con el que coincidimos. Por ende, este artículo pretende analizar también las continuidades y rupturas existentes entre las prácticas anteriores y posteriores que pueden observarse en torno a ese año, en este caso vinculadas al rol del Estado ante los conflictos obreros.

\subsection{UNA BREVE HISTORIA DEL DPT}

ElDPT se originó en un proyecto de ley presentado por los socialistas Adolfo Dickmann y Jacinto Oddoneen la Cámara de Diputados bonaerense en julio de 1914. Proponían la transformación de la "Oficina de Estadística" en una "Oficina de Estadística y del Trabajo", como había acontecido en otras provincias. Existían leyes laborales nacionales y el DNT funcionaba con su ley orgánica desde 1912, por lo cual los representantes socialistas estimaban que la provincia debía tener un organismo propio encargado de los 
asuntos laborales. El proyecto se convirtió en ley en diciembre de 1916, aunque la ley orgánica que reglamentó su funcionamiento recién se promulgó en 1937 (Corva \& García Bossio, 2003). Desde enero de 1917, la "Oficina de Estadística” se denominó “Dirección General de Estadística y Departamento de Trabajo". Ambos organismos se dividirían en junio de 1923 durante el gobierno del radical Cantilo (1922-1926), dependiendo desde ese momento la DGE del Ministerio de Hacienda; y el DPT del Ministerio de Gobierno, hasta que fue absorbido por el gobierno nacional a principios de 1944, cuando se convirtió en una "delegación regional" de la STyP (Campione, 2007: 110).

A inicios de la década de 1920, algunas provincias como por ejemplo Córdoba en 1922, introdujeron cambios en la organización de sus organismos laborales (Roggio, 2000: 413). En el caso del DPT bonaerense, en 1924 se crearon cuatro "delegaciones regionales y bolsas de trabajo" en Avellaneda, Bahía Blanca, Junín y Zárate-, que funcionaron sin dificultades entre 1925 y $1930 .{ }^{4} \mathrm{La}$ escasez de personal, la falta de presupuesto y la carencia de capacidad ejecutiva para imponer sus decisiones habrían conspirado contra la eficiencia de esas dependencias (Ascolani, 1994: 148). En general, en la mayor parte de las provincias pampeanas como Buenos Aires (Bejar, 2005), Córdoba (Roggio 2000; Ortiz Bergia, 2009: 2013), o Santa Fe (Piazzesi, 2013), los departamentos provinciales de trabajo incrementaron sus funciones tras 1930, al igual que en otras provincias como Mendoza (Garzón Rogé, 2013) y Tucumán (Ullivarri, 2013).

Desde sus orígenes el DPT colaboró con los poderes públicos cuando se requirió su asesoramiento. Y si bien la intervención del Estado provincial en las relaciones asalariadas se intensificó durante el gobierno de Manuel Fresco (1936-1940) ${ }^{5}$ tanto los gobiernos conservadores anteriores (1930-1936), como los gobiernos radicales que los antecedieron (1918-1930), ya habían señalado la obligación del Estado provincial de intervenir en las relaciones laborales. Así, por ejemplo, durante la gobernación del radical Crotto (1918-1921) en la cual se intensificaron los conflictos laborales protagonizados por los obreros rurales, el gobernador estableció a través de un decreto las disposiciones sobre el envío de trabajadores para el levantamiento de la cosecha. En dicha norma fue importante la participación de Aditardo Figueroa Ozzán quién, como Director del DPT, aportó el conocimiento adquirido sobre la problemática tras los viajes realizados a partidos afectados por el conflicto (Cuadrado Hernández, 1982: 88). También el gobernador José Luís Cantilo (1922-1926) presentó en su programa de gobierno proyectos que pretendían favorecer a los trabajadores desde el DPT. En su opinión, dicha dependencia debía asumir el control de la política laboral hasta que la provincia no tuviera un "Ministerio de Trabajo, Comercio e Industrias", política laboral que inspiraría una política de "unión de clases" (Diario de Sesiones del Senado de la Provincia de Buenos Aires, 1923: 39). ${ }^{6}$

\section{TANDIL Y EL MOVIMIENTO OBRERO A INICIOS DE LA DÉCADA DE 1920}

Fundada en 1823, la ciudad de Tandil se ubica en el sudeste bonaerense. Hacia 1880 su crecimiento se vinculó con la producción rural. También contribuía a ello el haberse constituido en un centro de abastecimiento de bienes y servicios cuya área de influencia abarcaba toda la región (Miguez, 1987: 351). La intensificación de dicha demanda regional de bienes y servicios facilitó la expansión de intereses administrativos, financieros y comerciales. Y el arribo del ferrocarril en 1883 incrementó el ritmo de llegada de los contingentes inmigratorios, posibilitando una mayor integración a los mercados nacionales e internacionales de su producción minera y agrícola.

Paulatinamente aparecieron numerosos talleres artesanales -herrerías, carpinterías, talabarterías, sastrerías, etc.-, e industrias rudimentarias, como fábricas de fideos, licores, chacinados y derivados de la leche, molinos harineros, hornos de ladrillos y jabonerías (Spinelli \& Zeberio, 1987). Pero con respecto a la demanda de mano de obra las actividades económicas más importantes fueron la agricultura y la minería (Velázquez, Lan \& Nogar, 1998), demanda que descendió a partir de 1930, al verse afectadas dichas actividades. Pero 
en las décadas anteriores el desarrollo de una estructura socio-económica heterogénea creó las condiciones necesarias para la generación de un movimiento obrero muy activo, en especial durante el período que aquí se considera, atrayendo la atención del gobierno provincial y de los funcionarios del DPT. ${ }^{7}$

Las primeras organizaciones obreras surgieron en Tandil a fines del siglo XIX. Fueron los gremios vinculados a actividades secundarias y terciarias, localizados de manera predominante en el medio urbano, los que más tempranamente se organizaron como sociedades de resistencia (en especial las de panaderos, sastres y costureras, tipógrafos y canteristas). La más antigua organización gremial de Tandil fue la de los cocheros, los cuales no se solían enfrentar con los patrones sino con las autoridades municipales. En 1885 realizaron una huelga por una ordenanza que los obligaba a estacionar solamente en dos espacios definidos, lo que motivo otra huelga por el mismo motivo en 1887; finalmente lograron la derogación de la ordenanza municipal tras dos semanas de huelgas (Spinelli \& Zeberio, 1987). Otro sindicato con una fuerte presencia en la ciudad fue el Centro de Empleados de Comercio. Creado en julio de 1902, desde 1904 se denominó Sociedad de Empleados de Comercio. Dicho sindicato se movilizaría posteriormente en torno a la aplicación y vigilancia de las leyes de descanso dominical y de jornada legal de trabajo.

Pero sin dudas el sindicato más activo fue el de los picapedreros, de orientación anarquista. Sus integrantes residían apartados de la ciudad, en las canteras de granito, teniendo escasa comunicación con el pueblo y con los demás gremios (Spinelli \& Zeberio, 1987), si bien eso no les impidió manifestar demandas en conjunto. La Sociedad Unión Obrera de las Canteras se creó en 1906. Ese mismo año realizaron la primera huelga, logrando que se aboliera el pago de salarios en vales, la libertad de tránsito y el acceso de los comerciantes a las canteras, y el aumento salarial. La mayor huelga la protagonizaron hacia octubre de 1908, que finalizó en septiembre de 1909, hecho conocido como la "gran huelga", durando once meses. Los obreros abandonaron el trabajo en una de las canteras solicitando el aumento de salarios y la reducción de la jornada laboral durante los cuatro meses de verano. Los empresarios despidieron a los obreros, exigiendo la entrega de las herramientas y el abandono de las viviendas. Al paralizarse las canteras, se afectó la pavimentación y el embellecimiento que se estaba realizando en la ciudad de Buenos Aires por los festejos del Centenario. La negociación final favoreció a los trabajadores, gracias a que la organización gremial alcanzada les permitió asegurarse la subsistencia, al abrir los picapedreros en huelga nuevas canteras y recibir los comerciantes de la ciudad como forma de pago la piedra que les entregaban a cambio de los repartos de víveres que hasta allí llevaban. La tensión social tuvo su punto culminante en 1911, cuando durante el carnaval de ese año bajaron los obreros de las canteras para solicitar la liberación de tres compañeros detenidos, enfrentándose con la policía (Nario, 1997).

El otro sindicato que demandó en reiteradas ocasiones reclamos públicamente en este período fueron los panaderos, que formaron su sociedad de resistencia en 1906. En julio de 1907, por diferencias con los empresarios panaderos, realizaron una huelga que duró 46 días. Salvo los cocheros y los dependientes de comercio, en esa ocasión el reclamo fue apoyado por todos los gremios, en especial aquellos bajo orientación anarquista. También llevaron a cabo otra huelga en enero de 1908 durante 29 días, obteniendo, entre otras conquistas, el descanso dominical con goce de sueldo y un kilo de pan diario (Spinelli\&Zeberio, 1987).

Los conflictos de las organizaciones obrera con los empresarios y con las autoridades policiales en Tandil fueron especialmente numerosos en dos oportunidades; primero entre 1909 y 1913 debido especialmente a las movilizaciones de los obreros canteristas; y luego entre 1918 y 1921, "época de gran alzamiento internacional de la clase obrera" (NE, 04/04/1923). Ambos períodos coincidían con momentos de gran movilización e impacto público del movimiento obrero en Argentina, en especial en grandes ciudades como Buenos Aires y Rosario.

A inicios de la década de 1920, el movimiento obrero tandilense estaba representado sindicalmente por la Federación Obrera Local (FOL), la Confraternidad Ferroviaria y algunos gremios autónomos. A la primera organización la integraban principalmente tres gremios de orientación anarquista (panaderos, picapedreros y trabajadores del campo), siendo en total cerca de 1.500 afiliados, muchos de los cuales se hallaban ausentes 
de la región. Por su parte, la Confraternidad Ferroviaria era una sección del organismo nacional y se había creado en la ciudad en 1922, integrada por los sindicatos La Fraternidad y Unión Ferroviaria.

Hacia 1921, el ya aludido impacto del "gran alzamiento internacional de la clase obrera" seguía afectando a Tandil. En marzo de ese año surgió un conflicto entre los obreros y los patrones panaderos que no pudo ser solucionado por las autoridades locales municipales ni por la policía. El día 16, la FOL comenzó una huelga por tiempo indeterminado en solidaridad con los obreros panaderos. Los gremios de albañiles, pintores, carpinteros, mecánicos, personal de la usina de la electricidad, algunos mozos de bares, la mayoría de los cocheros, y los peones municipales, entre otros, se plegaron al movimiento. Los obreros en huelga, distribuidos en comisiones por la ciudad, no dejaban que los lecheros ni los verduleros entregaran alimentos, intimándolos a abandonar los repartos bajo amenaza de represalias. Ante la solicitud de las autoridades locales de tendencia radical, el gobierno provincial envió un escuadrón de seguridad de diez agentes al mando de un sargento para garantizar el orden. También dispuso el viaje de un delegado del DPT para que interviniera en el conflicto. Dos días después, la FOL solicitó permiso para realizar un mitin (NE, 18/03/1921). En ese contexto, el delegado que llego a la ciudad en nombre del DPT fue el Director de dicho organismo, Aditardo Figueroa Ozzán. En el mitin, que se realizó el día 19, ocuparon la tribuna el representante de la FOL y un obrero canterista. Luego hizo acto de la palabra Figueroa Ozzán, que les pidió a los obreros que guardaran calma, señalando que había conseguido el permiso de la policía para que se realizara el acto bajo la condición de que fuera un mitin de información y que no fuera violento. Prometió dialogar con los patrones panaderos para que aceptaran el pliego de condiciones propuesto por los obreros, manteniendo conversaciones con ambos sectores. En vista de esa declaración, los oradores obreros pidieron que se disolviera en orden la concurrencia, especificando que si las seguridades dadas por el director del DPT no se cumplían la FOL iniciaría otras acciones. La intervención de Figueroa Ozzán solucionó el conflicto al establecerse un acuerdo, pese a la oposición de algunos patrones (NE, 19/03/1921).

Ese conflicto fue el más importante de 1921, y aunque los sindicatos obreros continuaron manifestando públicamente sus reclamos, las posteriores huelgas no fueron tan relevantes. Así, por ejemplo, en marzo de 1922 los obreros panaderos iniciaron otra huelga declarando el boicot a dos panaderías en las que trabajaban obreros no federados. Tras una asamblea el sindicato presentó un pliego de condiciones a ambas panaderías. El pliego fue cuestionado pero el 28 de marzo se llegó a un acuerdo tras mediar en el conflicto la FOL. Hacia junio de ese año, el secretario general del sindicato de los trabajadores panaderos fue detenido junto a otros cuatro obreros por infringir la ley sobre libertad de trabajo. Esto generó otra huelga de panaderos hasta su liberación el 10 de julio de 1922.

Entre junio de 1921 y octubre de 1922 además de los panaderos otros gremios se manifestaron públicamente, realizando numerosas asambleas para discutir asuntos gremiales. En conjunto realizaron al menos 35 asambleas, de las cuales 17 correspondieron a obreros picapedreros; 5 a carreros y changadores; 5 a conductores de vehículos; 2 a albañiles; 2 a obreros municipales; 2 a empleados de comercio; 1 a ladrilleros; $y$ 1 a molineros. ${ }^{8}$ Además de las asambleas, la actividad sindical también se manifestaba en otras dimensiones, como la organización de veladas y conferencias para festejar el día del trabajo. $\mathrm{O}$ en la emergencia de probables huelgas que finalmente no se realizaron, como la que en noviembre de 1921 estuvieron a punto de protagonizar los obreros picapedreros por la expulsión de un obrero. También durante todo este período la FOL organizó veladas y conferencias, y dos asambleas en junio de 1922 a raíz de la ya mencionada detención del secretario general del sindicato de los obreros panaderos.

Por ende, fue en ese marco que actuó el delegado del DPT en la ciudad serrana, en una coyuntura y en un espacio donde el movimiento obrero se hallaba organizado y se manifestaba frecuentementepara reclamar y defender sus derechos. 


\section{LA ACTUACIÓN DEL DELEGADO DEL DPT EN TANDIL}

En abril de 1921 el gobernador Crotto nombró a José Fiscalini delegado del DPT en Tandil. Pero la mayor parte de su actividad como delegado del DPT en aquella ciudad coincidió con la gobernación de Monteverde. Este era el vicegobernador, que debió asumir la gobernación ante la renuncia de aquel en mayo de 1921, debido a los conflictos intestinos que sufría el radicalismo bonaerense. ${ }^{9}$ El cambio de gobernador también provoco cambios en la dirección del DPT. Aditardo Figueroa Ozzán, responsable del organismo entre abril de 1919 y mayo de 1921, fue sucedido hasta junio de 1922 por el contador Augusto Brunell (De Luca, 2008: 163).

Pero para entender la designación de Fiscalini como delegado del organismo laboral en Tandil, más importante que el nombramiento de Brunell fue el arribo del escribano José Antonio Cabral como Ministro de Gobierno durante los últimos meses de gobierno de Crotto. Destacado dirigente radical de la provincia, Cabral fue nombrado comisionado municipal de aquella ciudad por la intervención de Cantilo entre 1917 y 1918. El primero de octubre de 1919 fundó el ya mencionado diario "Nueva Era" (Barrientos, 1975: 165), a la par que ejercía el cargo de senador provincial (1918-1920). Y desde el 10 de febrero hasta el 26 de abril de 1921, es decir, durante los últimos días de Crotto como gobernador, fue designado Ministro de Gobierno de la provincia (De Luca, 2008: 258). Por ende, a diferencia de la experiencia del DNT analizada por Suriano (2012: 42), el reclutamiento de José Fiscalini como delegado del DPT en Tandil no pareció vincularse con lógicas racionales sino con las relaciones personales y favoritismos políticos: Fsicalinino solo militaba en el radicalismo tandilense sino que también trabajaba como periodista en el diario Nueva Era (Barrientos, 1975: 167). ${ }^{10}$ Por ende, posiblemente su nombramiento se debió en principio a sus vínculos con Cabral. Y en segundo lugar, a la presencia de Figueroa Ozzán mediando en el conflicto de panaderos de marzo de 1921, experiencia que pudo haber llevado al Director del DPT (en ese cargo hasta mayo del mismo año como ya se mencionó), a creer necesaria la presencia de un funcionario del organismo en Tandil.

Ya existían otros antecedentes de nombramientos de delegados del DPT en la provincia. De acuerdo a Tomás Puig Lómez, Ministro de Gobierno durante los primeros años de la gobernación de Crotto, durante el año 1918 hubo en la Provincia 129 huelgas, "y una que otra" en el transcurso de 1919 (Provincia de Buenos Aires, 1919: 104). Con certeza esas movilizaciones obreras, que como se observó al contemplar el caso tandilense continuaron manifestándose en los años siguientes años, impulsó al gobierno a nombrar representantes del DPT no sólo en la sede del organismo ubicada en La Plata.

A fines de octubre de 1919 se creó en Avellaneda una delegación permanente del DPT con jurisdicción en todo ese partido (Registro Oficial de la Provincia de Buenos Aires, 1919: 806). El gobierno había tomado esa medida tras recibir una nota del Director del DPT en la que proponía crear delegaciones en diversos lugares de la provincia. Para ello se asignaron 150 pesos por mes para los gastos de su instalación, nombrándose a Placido Mostarain como su responsable, que ocuparía ese cargo en forma ad-honorem. Poco después, en enero de 1920 se creó otra delegación del DPT en Quilmes, siendo nombrado delegado Mariano Pastor, y asignándose una suma para gastos. El Poder Ejecutivo había tomado esa medida al ser "de urgente necesidad establecer nuevas delegaciones del DPT en las localidades donde los núcleos de población obrera han alcanzado una importancia visible y de acuerdo con lo pedido por la mencionada repartición" (Registro Oficial de la Provincia de Buenos Aires, 1920: 37). En mayo de 1920, Crotto mencionó ante la Legislatura que en el último año la DGE y DPT había realizado una amplia labor obstaculizada por la falta de personal, pues el presupuesto vigente solo le asignaba tres inspectores que debían controlar 59.309 establecimientos industriales y comerciales (Registro Oficial de la Provincia de Buenos Aires, 1920: 328).

El enero de 1921, el DPT propuso al gobierno mantener la delegación de Avellaneda creada en 1919. Se sostenía que debía seguir funcionando por haber aumentado la población obrera y los problemas relacionados con la misma. El Poder Ejecutivo provincial decidió mantener esa delegación del DPT (Registro Oficial de la Provincia de Buenos Aires,1921: 26). El nombramiento de más de una persona como funcionarios en 
esa delegación expone que muy tempranamente la importancia de ese espacio para la administración estatal bonaerense. ${ }^{11}$ Pocos años después, el Ministro de Gobierno de Cantilo sostuvo que los servicios de la oficina del DPT de Avellaneda habían sido sumamente deficientes al contar solamente con tres empleados. Además, su ubicación en una oficina de la comisaría local resultaba pésima pues estaba destinada "a los detenidos y a los vagos". Como ni el sitio ni el local eran propicios para una oficina que frecuentaban personas de ambos sexos y menores que allí debían gestionar su libreta de trabajo, se resolvió trasladar la repartición a un lugar más cómodo y adecuado a pesar de la escasez de recursos (Provincia de Buenos Aires, 1924a: 231).

La situación de las delegaciones mejoró al sancionarse la Ley de Presupuesto en mayo de 1923. Se consolidó la instalación de la Delegación Regional y Bolsa de Trabajo en Avellaneda, "el centro industrial más importante de la provincia", para atender servicios administrativos como la oferta y demanda de brazos o la certificación de aptitud para el trabajo de obreros y empleados. La experiencia se repetiría en Bahía Blanca, Junín y Zárate, en particular con el objetivo de equilibrar la oferta y demanda de brazos para los trabajos agrícolas (Provincia de Buenos Aires, 1924b: 277).

En ese marco, ¿cómo considerar la experiencia de Fiscalini, que a la postre no se convirtió en la experiencia inicial para crear una delegación en Tandil del DPT, a diferencia de lo que aconteció en otros espacios? En principio debe señalarse que su accionar no se asemejó a la de los inspectores del DPT ni a la de los funcionarios nombrados para actuar en las Delegaciones Regionales. Estos se especializaron en las nuevas problemáticas y normas que desde las agencias estatales se pensaron para estudiar e influir sobre el plano laboral, especialmente los inspectores, cuyo rol, salvo excepciones (Soprano 2010; Garzón Rogé, 2013; Landaburu, 2013) ha sido estudiado sobre todo para la década de 1930. En el caso de Fiscalini, su nombramiento como representante del DPT no le impidió seguir desarrollando sus actividades cotidianas paralelamente, por lo cual no puede afirmarse que se haya especializado en los problemas laborales como si lo hicieron los otrosfuncionarios del organismo ya mencionados.

La huelga de panaderos de marzo de 1921 permite observar que el gobierno provincial de Crotto también apeló al ya aludido binomio "integración-represión" para tratar dicho conflicto obrero, al enviar conjuntamente un escuadrón para reprimir a los huelguistas y a un delegado del DPT para negociar. A medida que el conflicto se desarrollaba la prensa local tandilense fue comprendiendo que Figueroa Ozzán no era solo el delegado del organismo. ${ }^{12}$ Además del poco conocimiento sobre las autoridades del organismo laboral, este hecho también permite observar la imposibilidad de las autoridades del DPT de intervenir en todos los conflictos obreros que surgían en el territorio provincial debido a la extensión territorial.

Un problema que aquejaba a los trabajadores era el cumplimiento de la ley de descanso dominical, cuyas violaciones generaban constantes denuncias sobre su incumplimiento, que se dirigían a la sede del DPT en La Plata. El nombramiento de Fiscalini como delegado en Tandil de aquel organismo se vinculó con la necesidad del Estado de vigilar el cumplimiento de leyes con gran repercusión en las sociedades del interior provincial, como lo era aquella. ${ }^{13}$ La misma afectaba especialmente a los empleados de comercio, que solicitaban al DPT que se vigilara el cumplimiento de esa ley en particular.

En ese marco se produjo el nombramiento por parte de la Dirección General de Estadística y Departamento del Trabajo del vecino José Fiscalini como su delegado en Tandil. Debería actuar en la forma establecida para los inspectores. Al igual que los demás delegados locales que ya actuaban en otros lugares, debería vigilar especialmente los mandatos de la ley de descanso dominical, "contravenidos en todos los distritos por numerosos y diversos gremios”. Es decir, tenía que vigilar su cumplimiento y denunciar a la dirección del DPT las faltas a la misma, aplicando las multas correspondientes; las mismas variaban según la reincidencia de los denunciados, pudiendo llegar hasta la prisión cuando por tercera o cuarta vez el comerciante diera motivos para la intervención del delegado (ET, 28/04/1921). El gobierno quería que laley de descanso dominicalse cumpliera estrictamente, pues era una ley infringida por la mayoría de los comerciantes, "a vista y paciencia de las autoridades encargadas de velar por su fiel cumplimiento". El comercio debía permanecer cerrado los domingos, pero se burlaba especialmente en los negocios que 
expendían bebidas alcohólicas. E informaba que denunciaría las contravenciones que se produjeran (NE, 10/06/1921).

Aunque en su designación se había establecido que Fiscalini debía actuar en la forma establecida para los inspectores, no actuaba sólo sino que acompañaba a los funcionarios que llegaban desde La Plata a inspeccionar los lugares de trabajo. Así, en julio de 1921 fue junto al inspector Arturo Romay a visitar establecimientos industriales de la localidad para comprobar el cumplimiento de las leyes del trabajo de mujeres y menores, observando numerosas contravenciones. ${ }^{14} \mathrm{El}$ mencionado inspector opinaba que el objetivo del DPT no era gravar las industrias florecientes, sino asegurar la higiene y comodidad de los obreros, que no parecían comprender los peligros a los que estaban expuestos y cuya solución no demandaría grandes gastos a los patrones. También señalaba que los funcionarios del organismo laboral debían intentar conciliar a las partes cuando se trataba de la ley sobre trabajo de mujeres y de menores, siendo más rígidos en el cumplimiento de las leyes laborales de descanso dominical y de accidentes de trabajo. También remarcó que de allí en más en Tandil sería Fiscalini quién entregaría las libretas del trabajo para menores, debiendo dirigirse a él los interesados en obtenerlas. El delegado también debería, ante las faltas de los patrones, proceder sin contemplaciones e imponer las penas establecidas (NE, 22/07/1921).

En octubre de 1921, Fiscalini publicó un aviso en la prensa en el que daba a conocer la dirección de su propio domicilio, invitando a los obreros que tramitaran a través de él los asuntos relacionados con el DPT. Informaba que estaba facultado para vigilar el cumplimiento de las leyes sobre accidentes de trabajo, sobre trabajo de las mujeres y menores, y sobre descanso dominical. Publicaba tal aviso debido a que en muchos asuntos en los que podía intervenir los obreros damnificados daban poder a gestores que actuaban en La Plata, mientras que los trámites podían ser gestionados directamente en Tandil y de forma oficial, evitando gastos (NE, 21/10/1921). Dicho aviso exponía que su rol como delegado del DPT no estaba muy difundido entre los obreros y empleados tandilenses.

Sin embargo, su intervención ante un reclamo obrero expone que la presencia de Fiscalini fue percibida como relevante para aquellos que necesitaron su mediación. El 11 de marzo de 1922 el picapedrero Eugenio Pérez sufrió un accidente en las canteras Nocelli. Producida una divergencia de opiniones entre el médico de la compañía aseguradora y un facultativo particular que asistió al paciente, la dirección del DPT tuvo en cuenta el informe que había enviado Fiscalini para ordenar el reconocimiento del accidentado por parte del médico de la repartición policial. El informe del mencionado facultativo fue favorable a la demanda del obrero. Ese detalle había sido omitido por la policía en el acta de verificación del accidente que servía de base para tramitar los expedientes (NE, 15/03/1922). Pérez se encontraba sin asistencia y sin recursos al no reconocer la compañía aseguradora el accidente. Por eso, tras conocer el diagnóstico del médico policial, la dirección del DPT facultó a Fiscalini para que escogiera un médico, mientras hacia trámites ante la compañía para que esta reconociera su responsabilidad y se hiciera cargo de la asistencia de Pérez. Todas esas gestiones tuvieron un resultado favorable al obrero, al recibir el accidentado una comunicación del DPT que le informaba que la compañía aseguradora reconocía su responsabilidad. Satisfecho por el reconocimiento de sus derechos, Pérez hizo públicas las diligencias realizadas por la dirección del organismo laboral y por Fiscalini, dejando constancia de su agradecimiento por la atención que había recibido (NE, 06/04/1922).

Otra intervención pública de Fiscalini de las que nos han quedado testimonios tuvo que ver nuevamente con una ley que había impulsado la presencia de delegados del DPT en el interior, la ley de descanso dominical. En mayo de 1922 la Sociedad Unión Empleados de Comercio envió una nota al DPT denunciando violaciones a dicha ley por numerosos comercios de la localidad. Debido a ese reclamo, Fiscalini elevó la denuncia para que se procediera en consecuencia tras constatar que la denuncia era verdadera (NE, 12/05/1922). Para ello solicitó el concurso policial al subcomisario a cargo de la comisaría, quien notificó a todos los comerciantes que debían respetar aquella norma.

Los patrones peluqueros fueron los que presentaron más resistencia. Estos consultaron sobre una concesión otorgada por un comisario que ya no estaba a cargo que había permitido que esos negocios 
funcionaran los domingos hasta el mediodía. Pero Fiscalini les respondió que la ley era terminante al exigir a las peluquerías que debían cerrar desde la medianoche del sábado hasta el lunes. Si había existido alguna contemplación ella había estado fuera de la ley, pues no había una cláusula que otorgara esa licencia (NE, 30/05/1922). Pocos días después los peluqueros volvieron a insistir en sus reclamos. Una comisión se acercó al subcomisario solicitando que se les otorgara un plazo para cumplir con la norma alegando la conveniencia de dar aviso a su clientela para evitar molestias. Dicho funcionario y Fiscalini accedieron a la petición disponiendo que a partir del domingo 18 de junio ninguna peluquería podría abrir desde el día sábado hasta el lunes (NE, 02/06/1922).

No obstante ello, un mes más tarde una comisión de la Sociedad Unión Patrones Peluqueros insistió con su demanda. Se entrevistó con el comisario de policía a fin de dejar establecido si podían trabajar el domingo, volviendo a obtener la misma respuesta (NE, 01/07/1922). A la semana, los peluqueros insistieron en su reclamo de trabajar, volviendo a obtener como respuesta la imposibilidad de infringirla sin caer en las penalidades que la misma estipulaba. Pocos días antes, el gremio de Balcarce se había dirigido directamente al Ministerio de Gobierno provincial, solicitando un permiso análogo que les fue negado (NE, 07/07/1922).

Sin embargo, ya desde julio de 1922 Fiscalini no estaba al frente de las respuestas que los peluqueros obtenían. El delegado debió dejar su cargo debido a recortes presupuestarios impuestos por el nuevo gobierno provincial, aunque trabajara en forma ad-honorem. Desde mayo de 1922 y hasta mayo de 1926 el gobernador Cantilo, como ya se mencionó, modificó la manera de relacionar al DPT con las localidades del interior. La instalación de las Delegaciones Regionales en lugar de los delegados locales que habían comenzado a trabajar un año antes en algunas localidades del interior, exponía que sus ideas con respecto a las de sus antecesores sobre cómo debía vincularse el organismo laboral provincial con las localidades del interior eran diferentes.

Dos opiniones posteriores nos permiten aproximarnos a la importancia que la experiencia del delegado local tuvo para Tandil.

La primera pertenecea Florentino Suárez, presidente del Sindicato de Empleados de Comercio. En agosto de 1930 le solicitó al diputado provincial Miguel Antonena su intervención para crear una delegación del DPT en Tandil, al igual que las existentes en otras cuatro ciudades. En su opinión en la ciudad no se vigilaba el cumplimiento de las leyes laborales que reclamaban una vigilancia directa y permanente por parte de las autoridades, pues en su opinión Tandil tenía mayor importancia comercial e industrial que otras ciudades que ya contaban con delegaciones, como Junín o Zárate. La nueva delegación podría tener jurisdicción sobre los partidos limítrofes, permitiendo una mayor vigilancia en la región (NE, 12/08/1930). Que haya sido el secretario del sindicato de los empleados de comercio quien solicitó la presencia de una delegación del organismo laboral provincial, expone la importancia que el organismo tenía para ellos, principales beneficiarios de las leyes de descanso dominical y de la jornada legal de trabajo.

Solo una decena de años más tarde se haría realidad ese deseo, cuando tras el golpe de junio de 1943 se instaló en la ciudad una sub-delegación de la STyP. En esa ocasión, la segunda opinión pertenece a la prensa, que respaldó el pedido de dicha representación debido al creciente desarrollo industrial del partido, vinculado a la industria metalúrgica que se había consolidado tras 1930. La única excepción hasta ese momento había sido la breve experiencia de José Fiscalini: aunque su figura había sido suprimida "por razones de economía", su actuación durante el corto tiempo que fue delegado había sido intensa y había demostrado "con la elocuencia de los hechos", la necesidad de tener representantes del DPT en la ciudad (NE, 21/02/1945).

\section{CONCLUSIONES}

El nombramiento a inicios de la década de 1920 de delegados locales directos del DPT en algunas ciudades bonaerenses fue una manera posible de pensar la relación entre ese organismo y las sociedades civiles del interior bonaerense. La misma no prosperó, al instalarse a posteriori en algunos puntos de ese espacio Delegaciones Regionales del organismo. Fueron dos formas diferentes de pensar la descentralización de la 
gestión que no parecen haber coexistido en el tiempo. Mientras que en algunos casos el nombramiento de un delegado culminó con la creación de una delegación regional del DPT (por ejemplo en Avellaneda), en otros casos parece haberse tratado de una experiencia aislada (como en Tandil).

La experiencia aquí analizada se inscribiría en la segunda etapa a la que hacía referencia Ortiz Bergia (2009: 152-153) al referirse a las políticas laborales articuladas desde el Estado. A pesar de los cambios que implicó la irrupción del radicalismo en el gobierno nacional y provincial, el binomio "integración-represión" para tratar la cuestión obrera permaneció, si bien se incorporaron nuevos actores a la sociedad política y se intentaron implementar nuevas formas de vincularse desde el gobierno a las problemáticas laborales.

La presencia de funcionarios del DPT en la ciudad fue discontinua y alterna, y siempre se solicitó que la presencia de ese organismo en la ciudad fuera mayor, salvo cuando Fiscalini actuó como delegado. Eso denota que su organización centralizada en La Plata y en algunas delegaciones no alcanzaba para dar cuenta de los conflictos y problemáticas laborales provinciales.

A partir de una mirada local, hemos comenzado a analizar su incidencia sobre la vida cotidiana de los obreros y empleados del interior provincial. Creemos que su impacto a nivel local fue relevante si se la contempla desde ese nivel. Además de efectos directos sobre algunos integrantes del mundo obrero, la intervención estatal en las relaciones laborales en el ámbito local también impactó de forma indirecta, al modificarse a partir de las nuevas leyes prácticas cotidianas, como lo expone el caso de los peluqueros y el corte de cabello los días domingo de parte de su clientela.

Lo que hemos podido hallar y analizar en este trabajo no nos permite cuantificarla actuación de Fiscalini, pero si calificarla como relevante si consideramos que durante el año que actuó como delegado del DPT, su presencia contribuyó a resolver y aclarar problemas que poco antes solo podían ser tratados a través de las fuerzas policiales. De hecho, tras la experiencia de aquel, gran parte de los conflictos continuaron siendo abordados por la policía provincial, que pretendía conocer y controlar el ritmo de la conflictividad obrera, además de tener la facultad de permitir o prohibir las reuniones obreras. Por ende, durante los primeros años de la década de 1920 aún la policía incidía en mayor medida sobre el movimiento obrero que el DPT y sus funcionarios.

En síntesis, a pesar de la ser una breve experiencia, la actividad de Fiscalini como delegado del DPT permite observar una manera inicial posible de haberse relacionado el DPT con las localidades del interior y sus limitaciones, en tanto su accionar parecía tener más éxito cuando era acompañado por inspectores del DPT o agentes policiales. También la naturaleza más política que administrativa del cargo, lo que no le proporcionaba estabilidad al mismo. En ese contexto, el nombramiento de un vecino antes que de un funcionario como delegado del DPT en una ciudad del interior tiene sentido, al constituirse en nexo entre los obreros, la policía y los inspectores de la repartición. Su ausencia, en los años venideros, acabaría con dicha articulación, lo que provocaría que los obreros debieran continuar realizando sus gestiones en la sede del organismo en La Plata. Y que las intervenciones posteriores del organismo laboral provincial estuvieran mediadas por los intereses policiales, surgiendo numerosas denuncias en las prensa sobre la "buena" o "mala" suerte que algunos comerciantes parecían tener a la hora de hacerse las inspecciones.

\section{FUENTES}

Diario Nueva Era, Tandil (1919-1945).

Diario de Sesiones de la Cámara de Senadores de la provincia de Buenos Aires (1921-1925). La Plata: Taller de Impresiones Oficiales.

Periódico El Eco de Tandil, Tandil (1917- 1930).

Provincia de Buenos Aires (1919). Memoria presentada a la Honorable Legislatura por el Ministro de Gobierno Dr. Tomás Puig Lómez, mayo de 1919. La Plata: Talleres de Impresiones Oficiales.

Provincia de Buenos Aires (1924b).Memoria presentada a la Honorable Legislatura por el Ministro de Gobierno Dr. José 
Trabajos y Comunicaciones, 2da. Época, № 48, e062, julio-diciembre 2018. ISSN 2346-8971

Osvaldo Casás, mayo de 1924. La Plata: Taller de Impresiones Oficiales.

Registro Oficial de la Provincia de Buenos Aires. La Plata: Taller de Impresiones Oficiales, varios años.

\section{ARTICULOS y LIBROS}

Ascolani, A. (1994). “Orígenes de la legislación laboral agraria en Argentina. Vinculaciones con la política y la economía, 1900-1930”. Anuario de la Escuela de Historia, No 16, pp. 145-161.

Auza, N. (1987). "La política del Estado en la cuestión obrera al comenzar el siglo XX: El Departamento Nacional del Trabajo, 1907-1912”. Revista de Historia del Derecho, No 15, pp. 101-140.

Bandieri, S. (1996). "Entre lo micro y lo macro: la historia regional. Síntesis de una experiencia”. Entrepasados, $\mathrm{N}^{\circ} 11$, pp. $71-100$.

Barandiarán, L. (2016). "La negociación colectiva antes del peronismo: el caso bonaerense (1935-1943)". Revista Anuario del Instituto de Historia Argentina, volumen 16, No 1, pp. 1-18.

Barrientos, J. (1975). Historia del periodismo de Tandil. Tandil: Grafitan.

Béjar, M. D. (1997)."El gobierno de Manuel Fresco. Entre la justicia social y el fraude patriótico”. Cuadernos del CISH, No 2/3, pp.79- 124.

Béjar, M. D. (2005). El régimen fraudulento. La politica en la provincia de Buenos Aires, 1930-1943. Buenos Aires: Siglo XXI Editores.

Bitrán, R.\& Schneider, A. (1991). El gobierno conservador de Manuel A. Fresco en la provincia de Buenos Aires (1936-1940). Buenos Aires: CEAL.

Bitrán, R. \& Schneider, A. (1993). “Coerción y consenso: la política obrera de Manuel Fresco (1936-1940)”. En Ansaldi, W., Pucciarelli A. \&Villarruel, J. (edits). Argentina en la paz de dos guerras, 1914-1945 (pp. 255-294). Buenos Aires: Editorial Biblos.

Campione, D. (2007). Orígenes estatales del peronismo. Buenos Aires: Miño y Dávila.

Corva, M. A. \& García Bossio, H. (2003). "El derecho laboral antes de Perón. Origen del Departamento de Trabajo de la Provincia de Buenos Aires". En Actas de las Primeras Jornadas de Historia Argentina. Hacia el Bicentenario de Mayo. La Plata: UCA.

Cuadrado Hernández, G. (1982). "La rebelión de los braceros”. Todo es historia, № 18, pp. 78-95.

Del Campo, H. (2005). Sindicalismo y peronismo. Los comienzos de un vínculo perdurable. Buenos Aires: Siglo XXI Editores. Trabajo original publicado en 1983.

De Luca, R. (2008). Funcionarios bonaerenses (1810-1950). Buenos Aires: Dunken.

Gaudio, R. \& Pilone, J. (1983). "El desarrollo de la negociación colectiva durante la etapa de modernización industrial en la Argentina. 1935-1943”. Desarrollo Económico, No 90, pp. 255-286.

Gaudio, R. \& Pilone, J. (1984). "Estado y relaciones laborales en el período previo al surgimiento del peronismo, 1935-1943”. Desarrollo Económico, No 94, pp. 235-273.

Garzón Rogé, M. (2013). “Las relaciones laborales en la mira del Estado provincial de Mendoza, 1916-1946”. En Lobato, M.\& Suriano, J. (comps.).Lasociedad del trabajo. Las instituciones laborales en la Argentina (1900-1955) (pp. 131-153). Buenos Aires: Edhasa.

Giacobone, C. \& Gallo, E. (1999). Radicalismo bonaerense. La ingeniería política de Hipólito Yrigoyen 1891-1931. Buenos Aires: Editorial Corregidor.

González Bollo, H. (Septiembre, 2003). “Aportes de los técnicos del Departamento Nacional del Trabajo a la cuestión obrera, 1907-1943”. En Actas de las IX Jornadas Escuelas/ Departamentos de Historia. Córdoba:Universidad Nacional de Córdoba.

Korzeniewicz, R. (1993). “Las vísperas del peronismo. Los conflictos laborales entre 1930 y 1943”. Desarrollo Económico, No 131, pp. 323-354.

Landaburu, A. (2013). "Los industriales y el Departamento Provincial del Trabajo ante el conflicto obrero de 1919 en Tucumán”. En Lobato, M. \& Suriano, J. (comp.). La sociedad del trabajo. Las instituciones laborales en la Argentina (1900-1955) (pp. 85-104). Buenos Aires: Edhasa. 
Lobato, M. \& Suriano, J. (2013). “Introducción. Trabajo, cuestión social e intervención estatal”. En Lobato, M. \& Suriano, J. (comp.). La sociedad del trabajo. Las instituciones laborales en la Argentina (1900-1955) (pp. 9-53). Buenos Aires: Edhasa.

Lvovich, D. \& Suriano, J. (2006). “Introducción”. En Lvovich, D. \& Suriano, J. (edits.). Las políticas sociales en perspectiva histórica. Argentina, 1870-1952 (pp. 9-23). Buenos Aires: Prometeo Libros.

Miguez, E. (1987). “Política, participación, poder. Los inmigrantes en las tierras nuevas de la provincia de Buenos Aires en la segunda mitad del siglo XIX”. Estudios Migratorios Latinoamericanos, No6/7, pp.337-379.

Murmis, M. \& Portantiero, J. C.(2004). Estudios sobre los origenes del peronismo. Buenos Aires: Siglo XXI Editores. Trabajo original publicado en 1971.

Nario, H. (1997). Los picapedreros.Tandil: Ediciones del Manantial.

Ortiz Bergia, M. J. (2009). "El intervencionismo estatal en el espacio provincial. Construcción de políticas laborales en Córdoba, 1930-1943”. Población y Sociedad, No 16, pp. 151-186.

Ortiz Bergia, M. J. (2013). "El tratamiento estatal de la "cuestión obrera" en Córdoba, 1930-1943". En Lobato, M. \& Suriano, J. (comps.), La sociedad del trabajo. Las instituciones laborales en la Argentina (1900-1955) (pp. 177-198). Buenos Aires:Edhasa.

Piazzesi, S. (2013). “La institucionalización del conflicto en Santa Fe durante la década de 1930”. En Lobato, M. \& Suriano, J. (comps.). La sociedad del trabajo. Las instituciones laborales en la Argentina (1900-1955) (pp. 199-219). Buenos Aires: Edhasa.

Reitano, E. (1992). Manuel A. Fresco, antecedentes del gremialismo peronista. Buenos Aires: CEAL.

Reitano, E. (2005). Manuel Antonio Fresco: entre la renovación y el fraude. La Plata: Instituto Cultural de la Provincia de Buenos Aires.

Revel, J. (1995). “Micro-análisis y construcción de lo social”, Anuario IEHS, N 10, pp.125-143.

Roggio, P. (2000). “El mundo del trabajo: discurso e instituciones del Estado. Córdoba, 1913-1943”. En Moreyra, B. (et. al.).Estado, mercado y sociedad. Córdoba, 1820-1950 (pp. 379-425). Córdoba: Centro de Estudios Históricos Prof. Carlos S. A. Segretti.

Ruffini de Grané, M. (1993). "Un aspecto de la relación Yrigoyen-Crotto. Agro y política en la provincia de Buenos Aires”. Estudios de Historia Rural III, Serie Estudios-Investigaciones, No15, pp. 33-58.

Soprano, G. (2000). "El Departamento Nacional del Trabajo y su Proyecto de Regulación Estatal de la Relación Capital-Trabajo en Argentina: 1907-1943”. En Panettieri, J. (comp.). Argentina: trabajadores entre dos guerras (pp. 31-53). Buenos Aires: Eudeba.

Soprano, G. (2010). "Haciendo inspección. Un análisis del diseño y aplicación de la inspección laboral por los funcionarios del Departamento Nacional del Trabajo (1907-1914)”. En Bohoslavsky E. \& Soprano G. (edits.). Un Estado con rostro humano. Funcionarios e instituciones estatales en Argentina (desde 1880 hasta la actualidad) (pp. 85-120). Buenos Aires: Prometeo Libros - Universidad Nacional de General Sarmiento.

Spinelli, M.\& Zeberio, B. (1987). "Inmigración y conflicto. Condiciones de vida y anarquismo en Tandil al comenzar el siglo XX”. En I Jornadas de Historia Regional Bonaerense (pp.177-197). Tandil: UNCPBA - Junta de Estudios Históricos de Tandil.

Suriano, J. (1989). "El Estado argentino frente a los trabajadores urbanos: política social y represión, 1880-1916”. Anuario de la Escuela de Historia, No 14, pp. 109-136.

Suriano, J. (2012). “El Departamento Nacional del Trabajo y la política laboral durante el primer gobierno de Hipólito Yrigoyen”. En Ben Plotkin, M. \& Zimmermann, E. (comps.), Los saberes del Estado (pp. 35-62). Buenos Aires: Edhasa.

Ullivarri, M. (2013). “Trabajadores, Estado y derechos. El Departamento Provincial del Trabajo tucumano durante la década de 1930". En Lobato, M.\& Suriano, J. (comps.), La sociedad del trabajo. Las instituciones laborales en la Argentina (1900-1955) (pp. 155-176). Buenos Aires: Edhasa.

Velázquez, G., Lan, D. \& Nogar, G. (comps.). (1998). Tandil a fin del milenio. Una perspectiva geográfica. Tandil: C.I.G-F.C.H/ UNCPBA. 
Zimmermann, E. (1995). Los liberales reformistas. La cuestión social en la Argentina (1890-1916). Buenos Aires: Editorial Sudamericana - Universidad de San Andrés.

\section{Notas}

* Agradezco los comentarios y sugerencias de los evaluadores anónimos del presente artículo.

1 Además de intervenir en los conflictos laborales, en principio intentando mediar y luego reprimiendo en general a los obreros, era la Policía la que debía vigilar el cumplimiento de algunas leyes obreras antes que surgiera el DPT. Así, hasta diciembre de 1916, la Policía vigilaba la aplicación de la ley de Descanso Dominical; otras agencias estatales tenían funciones similares, por ejemplo Dirección General de Estadística (de aquí en más DGE), que debía vigilar el cumplimiento en el territorio provincial de la ley que reglamentaba el trabajo de mujeres y de niños (Registro Oficial de la Provincia de Buenos Aires, 1916: 268-270). Al comenzar a funcionar el DPT, esta agencia se encargó de vigilar el cumplimiento de la legislación obrera, con el auxilio de la Policía, que tenía mayor cantidad de representantes a lo largo del territorio provincial.

2 La historiografía se ha ocupado en profundidad del DNT, contemplándose, entre otras cuestiones, la primera etapa de su organización (Auza, 1987); las tendencias políticas e ideológicas de sus funcionarios (Zimmermann, 1995); la persistencia de su "proyecto fundacional" (Soprano, 2000); sus vinculaciones con el gobierno nacional y las políticas laborales (González Bollo, 2003); y su transformación en la STyP hacia 1943 (Campione, 2007).

3 Un ejemplo de lo indicado por aquella autora para este último período fue la participación activa del DNT y de los departamentos provinciales de trabajo en la regulación estatal de las relaciones laborales, a través de la promoción de los contratos colectivos de trabajo, antecedente de los convenios colectivos celebrados bajo el peronismo (Murmis\&Portantiero, 2004; Del Campo, 2005; Gaudio \& Pilone, 1983, 1984; Korzeniewicz, 1993; Barandiarán, 2016).

4 También en otras provincias se observa la expansión de los organismos laborales en el interior provincial entre las décadas de 1920 y 1940. En Mendoza ya existían delegaciones en 1926, por ejemplo en San Rafael (Garzón Roge, 2013: 133). En Santa Fe, la ley 2.426 de mediados de la década de 1930 estableció consejos regionales de trabajo en Santa Fe, Rosario, San Urbano, Rafaela, Vera, Sastre, Gálvez y Casilda (Piazzesi, 2013: 201 y 217). En Tucumán, la presencia del DPT se centraba en su sede central y los lugares más cercanos a la capital provincial, si bien una ley de 1933 estableció una inspección general en Concepción, que aún no existía en 1939 (Ullivarri, 2013: 176). En Córdoba, hacia 1940 había delegaciones del DPT en Marcos Juárez, San Francisco, Cruz del Eje, Rio Cuarto y el Departamento de Punilla (Ortiz Bergia, 2013: 184).

5 Como ya se mencionó, Corva \& García Bossio (2003) analizaron los orígenes del DPT en la Legislatura bonaerense entre 1914 y 1916. Pero en general los trabajos historiográficos que han dado cuenta de aquel organismo estatal, a pesar de existir por casi tres décadas, se concentraron en el período 1936-1940, cuando gobernó la provincia el conservador Manuel Fresco. Varios autores que analizaron la gestión de ese gobernador se centraron en su política obrera, en general a partir de obras escritas por funcionarios provinciales. Esos estudios consideraron que durante esos cuatro años el DPT desempeñó un nuevo papel en la relación del Estado con el movimiento obrero, al intervenir de manera directa en la mayor parte de los conflictos entre capital y trabajo, lo que fue más sencillo tras sancionarse en 1937 su Ley Orgánica (Bitrán\& Schneider, 1991, 1993; Reitano, 1992, 2005; Bejar, 1997, 2005).

6 Debe recordarse que la preocupación de Cantilo por los problemas laborales no era nueva. Junto a Alfredo Palacios, fueron los autores de sendos proyectos a partir de los cuales se aprobó la ley orgánica del DNT en 1912 (Lobato \& Suriano, 2013: 21).

7 Coincidiendo con Soprano (2010: 86), en el caso aquí analizado se ha preferido utilizar la categoría de "funcionario" en lugar del concepto sociológico weberiano de "burocracia", por ser una categoría más abarcadora de las distintas dimensiones de análisis que se pretenden contemplar, al permitir designar tanto a los individuos que cumplían funciones en la gestión como a los demás integrantes de las organizaciones institucionales, en este caso del DPT.

8 Como ya se mencionó, en Tandil, al igual que ocurría en la ciudad de Buenos Aires, era la policía quien arbitraba en los conflictos laborales cuando lo requerían las partes involucradas (Lobato \& Suriano, 2013: 19), debiendo los sindicatos pedir permiso para celebrar sus asambleas; por eso, salvo que las reuniones fueran secretas, la información era publicada en la prensa como información policial.

9 Desde el ascenso de Yrigoyen a la presidencia en 1916, se habían perfilado en el radicalismo bonaerense dos tendencias, los "provincialistas" y los "metropolitanos". Los primeros se caracterizaron por ser nativos y estar afincados en la provincia, mientras que los segundos eran dirigentes vinculados al radicalismo porteño (Giacobone y Gallo, 1999: 199). Para las elecciones de 1918, la convención bonaerense radical votó como candidato a gobernador al "metropolitano" José Luis Crotto, y como vicegobernador al "provincialista” Monteverde, fórmula que a posteriori resulto electa. A 
pesar de un inicio auspicioso, Crotto debió renunciar tres años más tarde por las disputas emergentes en el seno del partido gobernante. Su enfrentamiento con Yrigoyen se habría basado en una diferencia de "criterios" sobre el personalismo presidencial, reflejando un conflicto latente entre la elite tradicional del radicalismo y la tendencia yrigoyenista sustentada en los sectores medios y los caudillos barriales (Ruffini de Grané, 1993: 34). Con su renuncia al gobierno elevada a la Legislatura provincial en mayo de 1921 y aceptada por unanimidad, Crotto evitó la intervención federal. El ingeniero Luis Monteverde se hizo cargo del gobierno hasta la finalización del mandato de la fórmula, desde el 20 de mayo de 1921 hasta el primero de mayo de 1922 (De Luca, 2008: 62). Lo sucedería otra fórmula radical, integrada nuevamente por un "metropolitano" (José Luis Cantilo), y un "provincialista” (Emilio Solanet).

10 Le agradezco la confirmación de estos datos al Dr. Leonardo Fuentes.

11 Así, por ejemplo, en octubre del mismo año el DPT propuso empleados para la delegación de Avellaneda, nombrando Auxiliar a Tito Ravani con antigüedad desde el 1 de septiembre en reemplazo de Miguel Protta que había sido dejado cesante; y Escribiente a Josefina C. de Luca en lugar de Carlos L. Alberti que había renunciado (Registro Oficial de la Provincia de Buenos Aires, 1921: 1478-1479)

12 Sin embargo, en anteriores ocasiones aquel ya había sido mencionado en la misma prensa. Así, por ejemplo, a fines de 1919 la prensa local informaba sobre las conferencias que estaba dando en las localidades de la provincia (ET, 09/ 11/1919). Más conocida fue su ya mencionada intervención a inicios del año siguiente en los conflictos desarrollados por los braceros en Tres Arroyos y Coronel Dorrego (ET, 04/01/1920).

13 A inicios de la década de 1920, el DPT debió vigilar el cumplimiento en territorio provincial de varias leyes obreras nacionales y sus correspondientes reglamentaciones provinciales, destacándose la de descanso dominical (ley 4.661 de 1904); las que reglamentaron el trabajo de mujeres y menores (ley 5.291 de 1907); la ley sobre indemnización por accidentes de trabajo (ley 9.688 de 1915); y la ley sobre trabajo a domicilio (ley 10.505 de 1918). Fuera del período aquí bajo estudio, otras leyes obreras sancionadas en la década de 1920 fueron: las que establecieron las modalidades para el pago de salarios en moneda nacional (ley 11.278 de 1923 y ley 11.337 de 1926); la nueva ley sobre el trabajo de mujeres y de menores (ley 11.317 de 1924); la ley que reglamentó el trabajo nocturno (ley 11.338 de 1926); y la que estableció la jornada laboral de ocho horas (ley 11.544 de 1929).

14 Así, por ejemplo, en una hilandería y fábrica de tejidos las obreras menores de edad no tenían las libretas de trabajo que exigía el DPT, por lo cual las mismas debieron retirarse del lugar (NE, 21/07/1921). 